DOI: $10.47456 / k r k r . v 1 i 5.32001$

\title{
Aprendendo ondulatória a partir do violão
}

Learning wave from the guitar

\author{
Ana Carolina Vieira Lourenço \\ João Matheus dos Santos Barbosa Villas Boas Maia \\ Nívea Fernandes Coutinho \\ Cleiton Kenup Piumbini \\ Luiz Otavio Buffon
}

\begin{abstract}
Resumo: Este artigo relata a construção, a aplicação e a avaliação de uma proposta de ensino de ondulatória utilizando-se a música, tendo como guia a teoria pedagógica de Paulo Freire. Durante as atividades, procurou-se relacionar a música e em especial o instrumento musical violão, com os princípios e conceitos da física relacionados a ondas e a acústica. Desta forma, procurou-se através da música contextualizar o ensino com aspectos culturais do cotidiano dos alunos dentro de um contexto freiriano. Esta proposta é fruto das atividades do PIBID (Programa Institucional de Bolsas de Iniciação à Docência) do subprojeto da Licenciatura em Física do IFES de Cariacica do ano de 2019 e foi realizada em 5 encontros com duas turmas do segundo ano na Escola Estadual de Ensino Fundamental e Médio (EEEFM) Agenor de Souza Le, no município de Vila Velha - ES. Os encontros foram realizados de forma dialogada sempre explorando os conhecimentos prévios dos alunos e priorizando os conceitos físicos. Ao final da intervenção, foi possível constatar que a abordagem conceitual, utilizando a música como tema, despertou considerável interesse dos alunos pela disciplina.
\end{abstract}

Palavras-chave: Ondulatória e Música. Pedagogia Freiriana. Violão na aula. PIBID.

Abstract: This article reports the construction, application and evaluation of a wave teaching proposal using music, using Paulo Freire's pedagogical theory as a guide. During the activities, we tried to relate music and especially the guitar musical instrument, with the principles and concepts of physics related to waves and acoustics. In this way, music was sought to contextualize teaching with cultural aspects of students' daily lives within a Freirian context. This proposal is the result of the activities of PIBID (Institutional Program for Teaching Initiation Scholarships) of the sub-project of the Physics Degree of IFES in Cariacica in 2019 and was held in 5 meetings with two classes of the second year at the State Elementary School and Medium (EEEFM) Agenor de Souza Le, in the municipality of Vila Velha - ES. The meetings were held in a dialogic way, always exploring students' previous knowledge and prioritizing physical concepts. At the end of the intervention, it was found that the conceptual approach, using music as a theme, aroused considerable interest from students in the discipline.

Keywords: Wave and Music. Freirian Pedagogy. Guitar in Class. PIBID.

\section{Introdução}

O ensino tradicional, centrado no professor, dificulta uma participação mais ativa dos alunos e o problema se agrava quando a aula não é planejada de forma contextualizada. Paulo Freire (1983) já alertava que nesse tipo de 
ensino os alunos não desenvolviam uma adequada autonomia, tendiam a apenas reproduzir o que Ihes era ensinado e tinham seu conhecimento prévio e sua realidade ignorados pelo professor.

O educador faz "depósitos" de conteúdos que devem ser arquivados pelos educandos. Desta maneira a educação se torna um ato de depositar, em que os educandos são os depositários e o educador o depositante. O educador será tanto melhor educador quanto mais conseguir "depositar" nos educandos. Os educandos, por sua vez, serão tanto melhores educados, quanto mais conseguirem arquivar os depósitos feitos. (FREIRE, 1983, p.66)

Deste modo, é importante que o professor sempre esteja motivado a testar novas metodologias de ensino e não fique preso a modelos tradicionais, pois essas novas experiências podem indicar métodos de ensino mais adequados. Nesse sentido as ideias de Freire vão ao encontro com a afirmação de Rogers (2009), de que a experiência é a autoridade suprema.

Assim, o objetivo deste artigo é relatar a construção, a aplicação e a avaliação de uma proposta dialógica de ensino de ondulatória, utilizando-se a música como elemento contextualizante e tendo como guia a teoria pedagógica de Paulo Freire. Acreditamos que a música seja uma boa aplicação dos conceitos de ondas e ao mesmo tempo seja um assunto que despertará grande interesse entre os alunos, por estar incorporado com a realidade deles.

A acústica é a parte da física que estuda as ondas sonoras, que se propagam em diversos meios materiais, principalmente no ar, sensibilizando no ouvinte o sentido da audição. Através da acústica é possível estudar o comportamento geral das ondas tendo a vantagem de que o objeto de estudo é um fenômeno do dia a dia das pessoas.

$\mathrm{Na}$ literatura encontramos trabalhos que demonstram a utilização da música como uma forma de ensinar a física relacionada às ondas, por exemplo, em Soares (2018), que elaborou uma proposta de ensino de acústica utilizando os instrumentos musicais, como tema e recurso central, dentro de uma metodologia dialógica de Paulo Freire. Santos, Molina e Tufaile (2013), elaboraram propostas utilizando os instrumentos musicais violão e guitarra para o estudo de conceitos de acústica através de experimentos. 
Os objetivos de ensino da proposta relatada neste trabalho foram ensinar os seguintes conceitos de ondas: frequência, período, velocidade da onda, amplitude, aplicações das ondas e instrumentos musicais, em particular o violão.

\section{Metodologia}

A proposta foi aplicada em duas turmas do segundo ano do ensino médio da escola Estadual de Ensino Fundamental e Médio (EEEFM) Agenor de Souza Le, no município de Vila Velha - ES. A intervenção ocorreu durante quadro dias, utilizando cinco aulas de 50 minutos e está descrita de forma resumida no quadro 1 , a seguir.

Quadro 1: Resumo da proposta didática aplicada nas duas turmas

\begin{tabular}{|l|l|lr|}
\hline $\begin{array}{l}\text { Encontro e } \\
\text { data }\end{array}$ & Atividade & Recursos \\
\hline $\begin{array}{l}1^{\circ} \text { Encontro } \\
04 / 04 / 2019\end{array}$ & $\begin{array}{l}\text { Apresentação da proposta de intervenção } \\
\text { e aula dialogada usando o violão e } \\
\text { desenhos de ondas no quadro. }\end{array}$ & $\begin{array}{l}\text { Aula experimental com } \\
\text { violão. }\end{array}$ \\
\hline $\begin{array}{l}2^{\circ} \text { Encontro } \\
11 / 04 / 2019\end{array}$ & $\begin{array}{l}\text { Aula dialogada aprofundando os conceitos } \\
\text { físicos discutidos no } 1^{\circ} \text { encontro. }\end{array}$ & Slides e discussões \\
\hline $\begin{array}{l}3^{\circ} \text { Encontro } \\
18 / 04 / 2019\end{array}$ & $\begin{array}{l}\text { Aula dialogada sobre os fenômenos } \\
\text { ondulatórios, interferência construtiva e e } \\
\text { destrutiva e ressonância. }\end{array}$ & $\begin{array}{l}\text { Slides, vídeos experimentos com uma } \\
\text { corda. }\end{array}$ \\
\hline $\begin{array}{l}4^{\circ} \text { Encontro } \\
02 / 05 / 2019\end{array}$ & $\begin{array}{l}\text { Aula dialogada sobre reflexão e refração } \\
\text { do som, Efeito Doppler e aplicações. }\end{array}$ & $\begin{array}{l}\text { Slides, vídeos e } \\
\text { discussões }\end{array}$ \\
\hline $\begin{array}{l}5^{\circ} \text { Encontro } \\
02 / 05 / 2019\end{array}$ & Avaliação sobre os conteúdos abordados. & $\begin{array}{l}\text { Teste escrito. } \\
\text { (Ver anexo 1) }\end{array}$ \\
\hline
\end{tabular}

Fonte: os autores

No $1^{\circ}$ encontro foi planejada uma apresentação lúdica sobre ondas, música e experimentos com um instrumento musical. Seriam apresentadas as notas musicais no violão com o intuito de relacionar a física com a música e com a introdução dos conceitos de acústica, tais como onda, frequência, representação de ondas senoidais, crista e ventre da onda, comprimento de onda, frequência, período, velocidade do som, timbre e amplitude (HALLIDAY, RESNICK E WALKER, 2010).

No $2^{\circ}$ encontro, foi planejado um aprofundamento dos conceitos introduzidos na aula anterior. Já nos $3^{\circ}$ e $4^{\circ}$ encontros foi planejado mostrar, através de slides e vídeos, exemplos do dia a dia envolvendo ondas e usando- 
se o experimento com uma corda, demonstrar os fenômenos da interferência construtiva e destrutiva.

A metodologia de Paulo Freire tem como foco a relação entre o professor e aluno, assim, é importante mostrar que os conhecimentos prévios dos alunos poderão ajudá-los em seus estudos. Essa atitude pode melhorar a autoestima do aluno e fazer com que ele participe ativamente no processo de aprendizagem, mostrando que o mesmo tem autonomia sobre o seu aprendizado.

O fundamental é que o professor e alunos saibam que a postura deles, do professor e dos alunos, é dialógica, aberta, curiosa, indagadora e não apassivada, enquanto fala ou enquanto ouve. O que importa é que professor e alunos se assumam epistemologicamente curiosos. Neste sentido, o bom professor é o que consegue, enquanto fala trazer o aluno até a intimidade do movimento de seu pensamento. Sua aula é assim um desafio e não uma "cantiga de ninar". Seus alunos cansam, não dormem. Cansam porque acompanham as idas e vindas de seu pensamento, surpreendem suas pausas, suas dúvidas, suas incertezas (FREIRE, 2002, 52).

\section{Relato dos Encontros}

$1^{\circ}$ encontro

A aula começou com a apresentação do tema que seria abordado (ver figura 1). Com a mediação de um dos autores tocando um violão foram demonstrados vários conceitos físicos tais como amplitude, frequência, bem como, as diferenças de sons devido ao timbre do instrumento. Foi exemplificado o que é um som grave e agudo e a diferença para som alto e baixo. Através de um desenho no quadro foi discutido o formato da onda senoidal, localizando-se o comprimento de onda, os ventres, as cristas e nó de uma onda. Tudo isso foi abordado a partir do violão, despertando um grande interesse nas turmas.

Nas duas turmas houve interesse no tema e surgiram dúvidas em relação aos conceitos físicos presentes na música e quanto a forma de tocar violão. Foi possível perceber que a maioria conseguiu compreender os conteúdos passados. 
Figura 1: Aula dialogada usando-se o violão no $1^{\circ}$ encontro

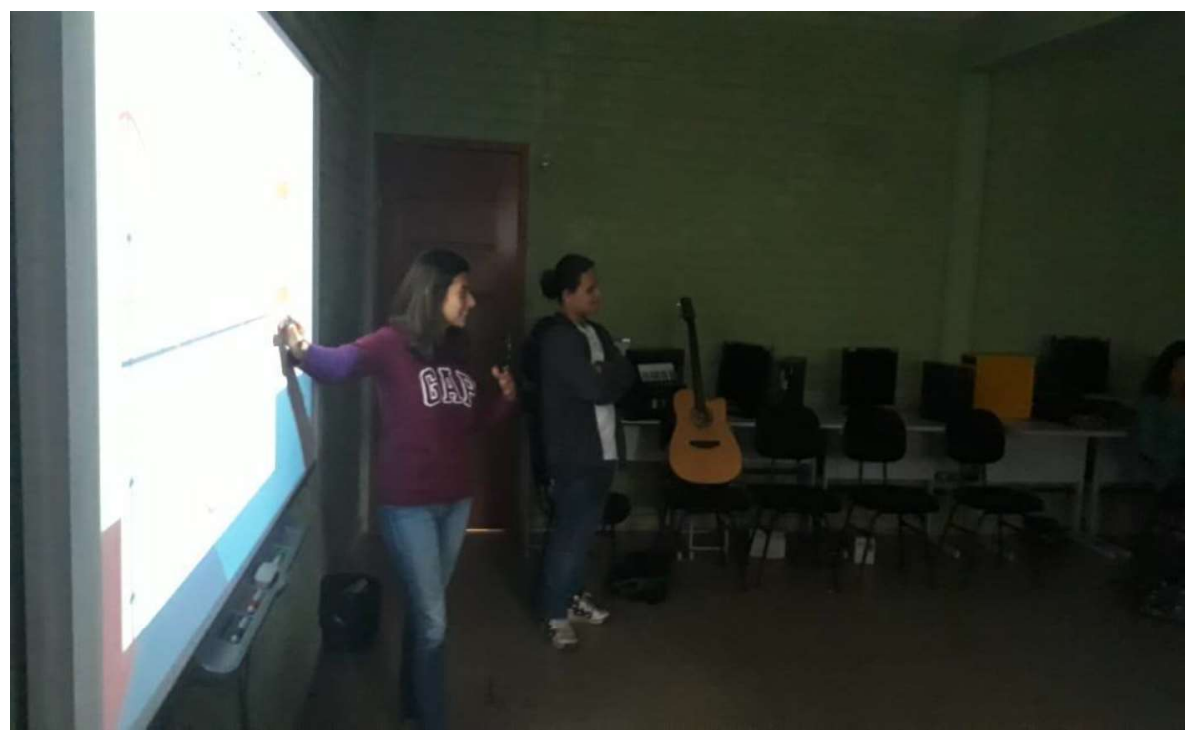

Fonte: arquivo pessoal dos autores

$2^{\circ}$ encontro

Iniciou-se com uma revisão do $1^{\circ}$ encontro, aprofundando-se os conteúdos de frequência e introduzindo-se os conceitos de período e velocidade de uma onda. Nas duas turmas, houve dificuldades para entender esses conceitos quando usávamos somente o formalismo matemático. Utilizando-se exemplos do cotidiano tais como analogias com período de rotação da Terra, comparações das velocidades da luz e do som, diferenças entre o relâmpago e trovão e frequência de um acontecimento periódico, foi possível contornar essa dificuldade.

A turma 1 conseguiu aprender com facilidade os conceitos de frequência e período de uma onda e lembravam bem dos conceitos da aula anterior. Já os alunos da turma 2 tiveram mais dificuldades do que a turma 1 nesses conceitos, lembravam pouco dos conceitos da aula anterior, mas conseguiram avançar com a introdução de exemplos práticos.

$3^{\circ}$ encontro

Foram discutidos os fenômenos da interferência construtiva e destrutiva e da ressonância através da experiência com uma corda (ver figura 2). Duas pessoas seguraram as pontas da corda e fazendo movimentos sacudindo-a 
para cima e para baixo foi possível ilustrar esses fenômenos. Através de slides e vídeos foram mostrados exemplos de ressonância, tais como uma ponte se quebrando por causa de um vento forte e uma taça de cristal se partindo com a voz de um homem.

Figura 2: Aula dialogada usando-se o violão no $1^{\circ}$ encontro

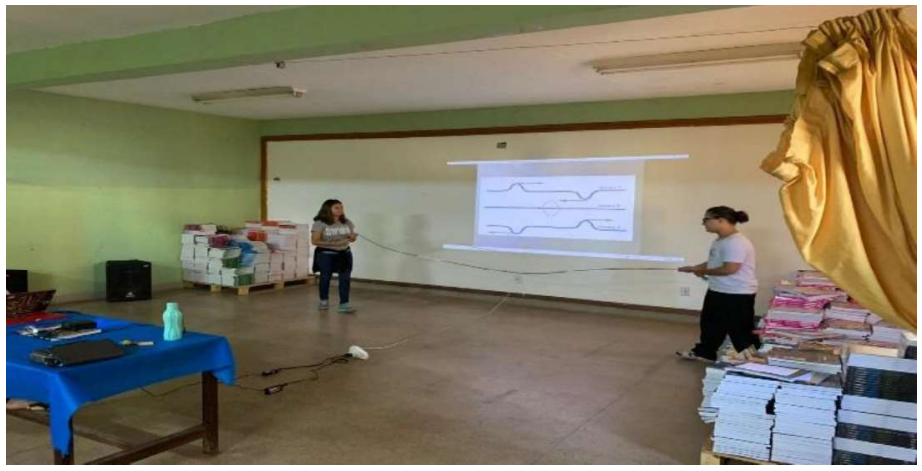

Fonte: arquivo pessoal dos autores

As duas turmas interagiram bem com os exemplos discutidos e ficaram interessados nos vídeos e no experimento com a corda.

$4^{\circ}$ encontro

Foram discutidos os fenômenos da reflexão, refração e Efeito Doppler para ondas sonoras. Na reflexão, foram mostradas imagens sobre aplicações do eco e da reverberação, como: ecografia, eco localização, sonar e acústica adequada numa sala. No efeito Doppler foi mostrado um vídeo para exemplificar como esse efeito acontece numa rodovia.

Nesse encontro, juntamos as duas turmas para aproveitar e fazer uma avaliação final no mesmo dia. Ao fazer isso, esperávamos que os alunos ficassem mais motivados com a presença de colegas novos em aula, porém acabou gerando uma desconcentração que dificultou a concentração deles nas atividades.

\section{$5^{\circ}$ encontro}

Nesse último encontro foi aplicado uma avaliação com cinco questões (ver anexo 1). A primeira questão explorou as diferenças entre os conceitos de frequência, amplitude e timbre com uma imagem mostrando duas ondas e 
perguntando qual representava uma onda sonora grave, aguda, alta ou baixa. A segunda questão envolvia um simples cálculo e uso da relação matemática entre velocidade da onda, frequência e comprimento de onda. A terceira questão explorou as diferenças entre as interferências construtiva e destrutiva no que se refere ao tipo de fase que as gera e a amplitude da onda resultante da superposição de ondas. Na quarta questão foi colocada uma situação problema e era necessário identificar o fenômeno físico mais adequado para descrevê-lo. Na quinta e última questão, era para relacionar eco e reverberação com suas aplicações.

No quadro 2, a seguir, apresentamos os percentuais de acertos das questões nas duas turmas 1 e 2.

Quadro 2: Percentuais de acertos das questões nas duas turmas 1 e 2

\begin{tabular}{|l|l|l|}
\hline Questões & Turma 1 & Turma 2 \\
\hline Número 1 & $76 \%$ & $85,7 \%$ \\
\hline Número 2 & $28 \%$ & $9,5 \%$ \\
\hline Número 3 & $84 \%$ & $81 \%$ \\
\hline Número 4 & $56 \%$ & $76,2 \%$ \\
\hline Número 5 & $72 \%$ & $42,9 \%$ \\
\hline
\end{tabular}

Fonte: os autores

O percentual médio de acertos da turma 1 no teste foi de $63 \%$ enquanto na turma 2 foi de $59 \%$. A maioria dos alunos das duas turmas errou a questão 2 , sendo que $28 \%$ a acertaram na turma 1 e somente 9,5 a acertaram na turma 2. Assim, em relação ao teste, a maioria dos alunos das duas turmas ficou acima da média.

\section{Considerações Finais}

Já era conhecido que as duas turmas apresentavam dificuldades com a parte matemática e na aplicação de fórmulas físicas, por isso, o conteúdo passado teve como foco a parte conceitual. Apesar disso, no teste foi colocada uma questão bem simples de aplicação direta de fórmula da equação da onda e o índice de erros foi muito alto, comprovando assim, a dificuldade com a parte matemática. 
Em relação a parte conceitual, o percentual de acertos das duas turmas foi relativamente satisfatório, ficando a turma 1 acima da média com $63 \%$ de acertos e a turma 2 quase na média com $59 \%$. Este resultado mostra que uma proposta didática dialógica para o ensino de ondas, usando a música como elemento contextualizante, constitui-se uma boa alternativa principalmente em turmas de ensino médio que apresentam dificuldades com a parte matemática. Sobre a proposta didática podemos acrescentar também que foi bem aceita pelas duas turmas.

\section{Agradecimentos e créditos}

Agradecemos ao Instituto Federal de Educação, Ciência e Tecnologia do Espírito Santo (IFES), Campus Cariacica, pela oportunidade de participarmos do Programa Institucional de Bolsas de Iniciação à Docência (PIBID) e à CAPES por financiá-lo.

\section{Referências}

FREIRE, Paulo. Pedagogia do oprimido. 12.ed. Rio de Janeiro: Paz e Terra, 1983.

FREIRE, Paulo. Pedagogia da autonomia: saberes necessários à prática educativa. São Paulo: Paz e Terra, 2002.

HALLIDAY, David; RESNICK Robert; WALKER Jearl. Fundamentos de Física. Trad. de Ronaldo César de Biasi. 8.ed. Rio de Janeiro: editora LTC, 2010.

ROGERS, Carl R. Tornar-se Pessoa. Trad. de Manuel José do Carmo Ferreira. 6.ed. São Paulo: WMF Martins Fontes, 2009.

SANTOS, E.; MOLINA, C.; TUFAILE, A. Violão e guitarra como ferramentas para o ensino de física. Revista Brasileira de Ensino de Física, v. 35, n. 2, p. 2507, 2013.

SOARES, Diego Novaes. 0 ensino de acústica através do uso de instrumentos musicais: uma proposta de ensino utilizando os 3 momentos pedagógicos. 2018. 98p. Dissertação (Mestrado Nacional Profissional em Ensino de Física). Instituto Federal do Espírito Santo, Campus Cariacica, Cariacica - Espírito Santo, 2018. Disponível em: https://sucupira.capes.gov.br/sucupira/public/consultas/coleta/trabalhoConclusa o/viewTrabalhoConclusao.jsf?popup=true\&id_trabalho=7376278. Acesso em 12/02/2020. 
Anexo 1

Teste aplicado no $5^{\circ}$ encontro
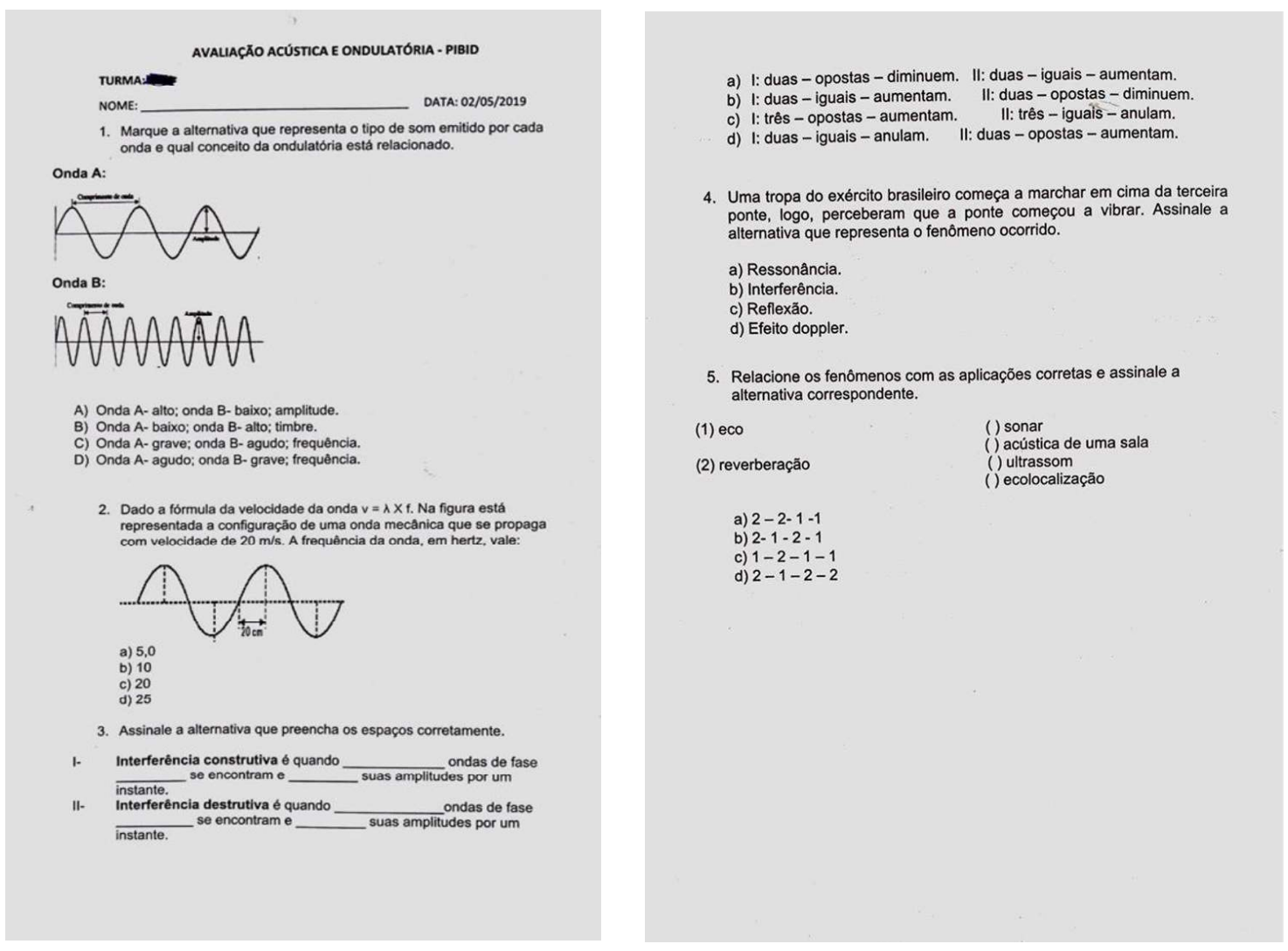

\section{Sobre os autores}

\section{Ana Carolina Vieira Lourenço}

anacvlourenco@gmail.com

Cursando Licenciatura em Física no Instituto Federal do Espírito Santo desde 2018/2, atualmente está no quinto período. Participou do Programa Institucional de Bolsa de Iniciação à Docência (PIBID) no período de março de 2019 a janeiro de 2020. 


\section{João Matheus dos Santos Barbosa Villas Boas Maia}

joaomatheussbvbmaia@gmail.com

Cursando Licenciatura em Física no Instituto Federal do Espírito Santo desde 2018/2. Participou do Programa Institucional de Bolsa de Iniciação à Docência (PIBID) no período de março de 2019 a janeiro de 2020.

\section{Nivea Fernandes Coutinho}

niveafer@hotmail.com

Graduada em Física pela Universidade Federal do Espírito Santo (2000), especialista em Metodologia do Ensino de Matemática e Física pelo Instituto superior de Educação Ateneu - ISEAT (2016). Atualmente, é professora da Rede Estadual do Estado do Espírito Santo, onde desenvolve atividades de ensino, orientação e desenvolvimento.

\section{Cleiton Kenup Piumbini}

cleiton.kenup@Ifes.edu.br

Possui graduação em Física pela Universidade Federal do Espírito Santo (2005), mestrado em Física pela Universidade Federal do Espírito Santo (2008) e doutorado em Física pela Universidade Federal do Espírito Santo (2013). Atualmente é professor do Instituto Federal de Educação, Ciência e Tecnologia do Espírito Santo, atuando principalmente nos seguintes temas: Ensino de Física, Plasma spray e $\mathrm{SmBa}_{2} \mathrm{Cu}_{3} \mathrm{O}_{7}$. Pertence ao Grupo de pesquisa NEEF (Núcleo de Estruturação do Ensino de Física)

\section{Luiz Otavio Buffon}

buffon@ifes.edu.br

Bacharel em Física pela Universidade Federal do Espírito Santo (1989), Mestre (1992) e Doutor (1998), ambos em Física das Partículas Elementares pela Universidade de São Paulo. Bolsista Recém-Doutor pela Universidade Federal do Espírito Santo (1999). Atualmente é professor 40 horas com dedicação exclusiva do Instituto Federal de Educação, Ciência e Tecnologia do Espírito Santo (IFES) - Campus Cariacica, atuando nos Cursos de Ensino Médio Técnico Integrado, Graduações e também no Mestrado Nacional Profissional em Ensino de Física. No momento estou orientando dissertações de Mestrado, projetos de iniciação científica, iniciação à docência (PIBID) e iniciação à extensão. Atuo na área de ensino de Física. Tenho experiência também nas áreas de Física Teórica. Pertenço ao Grupo de pesquisa NEEF (Núcleo de Estruturação do Ensino de Física). 